MacKay HM. Anaemia in infancy: its prevalence and prevention. Arch Dis Child 1928:3:117-47. Mackay HMM, Goodfellow L. Nutritional anaemia in infancy, with particular reference to iron deficiency. Medical Research Council Special Report Series 1931. No 157. Child 1933:8:221-5.

Burman D. Haemoglobin levels in normal infants aged 3 to 24 months, and the effect of iron. Arch Dis Child 1972;47:261-71.

5 Aukett MA, Parks YA, Scott PH, Wharton BA. Treatment with iron increases weight gain and psychomotor development. Arch Dis Child 1986;61:849-59.

6 Saarinen VM, Siimes MA. Iron absorption from breast milk, cows' milk, and iron supplemented formula: an opportunistic use of changes in total body iron determined by haemoglobin, ferritin and body weight in 132 infants. Pediatr Res 1979;13:143-9.
7 Mackay HMM Secondary anaemia in infancy. Lancet 1923;ii:165-8.

Oski FA, Stockman JA. Anemia due to inadequate iron sources or poor iron utilisation. Pediatr Clin North Am 1980;27:237-52.

9 Zeigler EE, Fomon SJ, Nelson SE, et al. Cow milk feeding in infancy: further observations on blood loss from the gastrointestinal tract. F Pediatr 1990;116:11-8.

10 Lundstrom U, Siimes MA, Dallas PR. At what age does iron supplementation become necessary in undstrom U, Siimes MA, Dallas PR. At what age does
low birthweight infants? F Pediatr 1977;91:878-83.

11 World Health Organisation. Nutritional anaemias. WHO Tech Rep Ser 1968; No 405:1-27.

12 Addy DP. Happiness is: iron. BMF 1986;292:969-70.

13 Oppenheimer SJ. Iron and infection: the clinical evidence. Acta Paediatr Scand 1989;362(suppl): $53-62$

\title{
New dietary reference values
}

\section{With an exemplary literature review thrown in}

The decennial revision of Recommended Daily Amounts of Food Energy and Nutrients for Groups of People in the United Kingdom $(1979)^{1}$ was a deeply unsatisfactory exercise for all concerned. A panel of nutrition scientists with inadequate data struggled to answer the question: "What average daily intake of nutrient $\mathrm{x}$ would meet the requirements of practically all members of a group?" The answer "We do not know," was not acceptable if only because the law required food labels to express some nutrients in the food as a proportion of the recommended daily amount - so a best guess was made. As a small part player in both the 1969 and 1979 reviews I can confirm that no self respecting scientist could derive any professional satisfaction from those miserable little pamphlets.

The politicians, who commissioned the reviews, were also unsatisfied as the frailty of their scientific basis was all too easily revealed. Questions like, "Is the minister aware that half my constituents have an intake of nutrient $x$ which is less than the intake recommended by his expert panel?" got the rather lame answer that recommended daily amounts applied to groups, not individuals, so it was really quite all right that some people got below the recommended daily amounts so long as not everyone did. Ministers couldn't "explain why, when surveys consistently show that energy intakes are below the recommended daily amounts, obesity is rapidly increasing in this country" other than by saying that an expert panel was working on it.

And of course the public was unsatisfied, mainly because the recommended daily amounts were given only for energy; protein; thiamine; riboflavin; nicotinic acid; folate; vitamins $\mathrm{C}, \mathrm{A}$, and D; calcium; and iron (and one of those, folate, was subsequently quietly disowned owing to doubts about the assay). For another 30 nutrients the scientists' answer, "We do not know," was perforce accepted.

The latest revision was published this week. ${ }^{2}$ Although close scrutiny may in time uncover flaws, there is no doubt that this version is a vast improvement on its predecessors. It is a volume of 210 pages (compared with 43 in 1969 and 27 in 1979): it provides reference nutrient intakes (the renamed recommended daily amounts) for 35 nutrients instead of 10 , and it also offers two more useful figures - the estimated average requirement and the lower reference nutrient intake, below which deficiency is probable. For many nutrients there is a note about the safety (or otherwise) of very high intakes.
There are informative chapters about energy, fat, non-starch polysaccharides (which yesterday's men call fibre), sugars, starches, and protein; one for each vitamin (and one for pseudovitamins like pangamic acid and laertrile); and one each for calcium, magnesium, phosphorus, sodium, potassium, chloride, iron, zinc, copper, selenium, molybdenum, manganese, chromium, iodine, fluoride, and "other minerals." The text is clear, to the point, and well referenced: the chapters on fat ( 92 references) and non-starch polysaccharides ( 53 references) are reviews that I shall consult frequently. The literature review is amazingly up to date: surely the reference to Law et al (BMF 1991;302:811) must have been inserted at the proof stage.

So what is new about the estimated requirements? As expected, estimated energy requirements are reduced, especially for women and during pregnancy. The components of energy intake are given as proportions of the total with and without alcohol. The average proportion of total energy from saturated fat is set at $10 \%$, cis-monounsaturated fatty acids at $12 \%$, cis-polyunsaturated fatty acids $6 \%$, trans-fatty acids $2 \%$, non-milk extrinsic sugars $10 \%$, and other sugars and starches $37 \%$; and daily intake of non-starch polysaccharides is set at $18 \mathrm{~g}$. The reference nutrient intake for adults for sodium is $70 \mathrm{mmol} /$ day $-\mathrm{a}$ big change from the present average British diet but in line with expert consensus. The reference nutrient intake for vitamin $\mathrm{C}$ is modestly increased (from 30 to $40 \mathrm{mg} / \mathrm{day}$ ); for calcium it is increased from 500 to $700 \mathrm{mg} /$ day, but an excellent review chapter (43 references) points out that isotope studies have shown rates of absorption ranging from $18 \%$ to $46 \%$. This means that for calcium, as with iron, bioavailability is at least as important as the amount in the diet.

This report has been a long time coming - the panel was convened in 1987-but an excellent job has been done. The task of the next revision panel (in 2001?) will be both easier and more enjoyable than that of the last.

\section{JOHN GARROW}

Rank Professor of Human Nutrition,

Medical College of St Bartholomew's Hospital,

London EC1M 6BQ

1 Department of Health and Social Security. Recommended daily amounts of food energy and nutrients for groups of people in the United Kingdom. London: HMSO, 1979.

Panel on Dietary Reference Values of the Committee on Medical Aspects of Food Policy. Dietary reference values for food energy and nutrients for the United Kingdom. London: HMSO, 1991. 